J. H. Kim • H. D. Shin • B. L. Park • Y. M. Cho •

S. Y. Kim • H. K. Lee $\cdot$ K. S. Park

\title{
Peroxisome proliferator-activated receptor gamma coactivator 1 alpha promoter polymorphisms are associated with early-onset type 2 diabetes mellitus in the Korean population
}

Received: 7 November 2004 / Accepted: 28 February 2005 / Published online: 4 June 2005

C) Springer-Verlag 2005

\begin{abstract}
Aims/hypothesis: Peroxisome proliferator-activated receptor gamma coactivator 1 alpha $(\mathrm{PGC}-1 \alpha)$ is a transcriptional coactivator implicated in insulin release by beta cells and in insulin resistance. Therefore, genetic variation of PPARGC1A could be implicated in the onset of type 2 diabetes. In this study, we examined whether the PPARGC1A gene locus is associated with type 2 diabetes mellitus. We also investigated its association with clinical and metabolic parameters in healthy and diabetic subjects. Methods: After sequencing exons and their boundaries of the PPARGC1A gene, including the promoter region $(\sim 1.5$ $\mathrm{kb}$ ), we genotyped eight common single nucleotide polymorphisms (SNPs) in an association study comprising 762 unrelated patients with type 2 diabetes and 303 non-diabetic control patients. We divided the patients with type 2 diabetes into quartiles or three groups according to age at diagnosis of type 2 diabetes (early-onset: $<40$ years of age, average-onset: $40 \leq<60$ years, and late-onset: $\geq 60$ years). Results: There was no strong association between SNPs or haplotypes of PPARGC1A and type 2 diabetes. However, the SNPs of g. $-1789 \mathrm{G}>\mathrm{A}$ and g. $-1437 \mathrm{C}>\mathrm{T}$ were associated with the age at diagnosis of type 2 diabetes ( $p=0.042$ and $p=0.032$, respectively). In addition, the promoter SNPs of g. $-1789 \mathrm{G}>\mathrm{A}$ and g. $-1437 \mathrm{C}>\mathrm{T}$ and the haplotypes $h t 2$ $(-1789 \mathrm{~A}$ and $-1437 \mathrm{~T})$ were significantly associated with
\end{abstract}

J. H. Kim · Y. M. Cho · S. Y. Kim · H. K. Lee · K. S. Park $(\bowtie)$

Department of Internal Medicine,

Seoul National University

College of Medicine,

28 Yongon-Dong, Chongno-Gu,

Seoul, 110-744, South Korea

e-mail: kspark@snu.ac.kr

Tel.: +82-2-7601789

Fax: $+82-2-36768309$

J. H. Kim · Y. M. Cho · H. K. Lee · K. S. Park

Genome Research Center for Diabetes and Endocrine Disease, Clinical Research Institute, Seoul National University Hospital, Seoul, South Korea

H. D. Shin · B. L. Park

Department of Genetic Epidemiology, SNP Genetics,

Seoul, South Korea early-onset type 2 diabetes ( $p=0.002, p=0.001$ and $p=0.001$, respectively). Conclusions/interpretation: Our results suggest that PPARGC1A promoter polymorphisms are associated with age at diagnosis of type 2 diabetes and early-onset type 2 diabetes in the Korean population.

Keywords Early-onset type 2 diabetes P Peroxisome proliferator-activated receptor gamma coactivator 1 alpha $($ PGC- $1 \alpha) \cdot$ Polymorphism

Abbreviations LD: linkage disequilibrium - HOMA-IR: homeostasis model assessment of insulin resistance. MEF-2C: myocyte-specific enhancer factor $2 \mathrm{C} \cdot \mathrm{PGC}-1 \alpha$ : peroxisome proliferator-activated receptor gamma coactivator 1 alpha - SNP: single nucleotide polymorphism

\section{Introduction}

Peroxisome proliferator-activated receptor gamma coactivator 1 alpha $(\mathrm{PGC}-1 \alpha)$ is a transcriptional coactivator involved in the regulation of several key metabolic processes associated with type 2 diabetes, including adaptive thermogenesis, beta oxidation of fatty acid, insulin release by the beta cell, hepatic gluconeogenesis and glucose utilisation in peripheral tissues [1-5]. PGC- $1 \alpha$ stimulates mitochondrial biogenesis and respiration by regulation of uncoupling proteins and nuclear respiratory factors [1]. In addition, increased expression of PGC- $1 \alpha$ in pancreatic beta cells has been reported to blunt the glucose-induced increase in cellular ATP levels and insulin exocytosis [2]. PGC- $1 \alpha$ stimulates hepatic gluconeogenesis and fatty acid oxidation by interaction with hepatocyte nuclear factor 4 alpha (HNF-4 $\alpha$ ), the forkhead transcription factor 1 (FOXO1) and peroxisome proliferator-activated receptor alpha (PPAR- $\alpha$ ) $[3,4]$. Furthermore, hepatic PGC- $1 \alpha$ expression increases in a mouse model of diabetes, and PGC$1 \alpha$ deficiency in diabetic mice, generated by adenoviral delivery of PGC- $1 \alpha$ siRNA to the liver, improves glucose tolerance [6]. In contrast, PGC-1 $\alpha$ increases glucose transporter 4 expression via coactivation of myocyte-specific 
enhancer factor 2C (MEF-2C) and thereby enhances glucose uptake in the skeletal muscle [5]. Skeletal muscle expression of PGC- $1 \alpha$ was reduced in both type 2 diabetic patients and non-diabetic subjects with family history of type 2 diabetes in comparison with control subjects $[7,8]$. Finally, previous reports have shown linkage of the PPARGC1A genomic region on chromosome 4p15.1 with fasting insulin concentration in Pima Indians and with BMI in Mexican Americans [9, 10]. Therefore, genetic variation of PPARGC1A has been implicated in the onset of type 2 diabetes [11]. Until now, single nucleotide polymorphisms (SNPs) in the transcribed sequence of PPARGC1A have been associated with type 2 diabetes in Danish and Japanese, but not in French and Pima Indian populations [12-15]. Recently, promoter SNPs have been reported to affect transactivation in an allele-specific manner and to be associated with carbohydrate metabolism [16]. In this study, we examined whether the PPARGC1A gene locus is associated with type 2 diabetes mellitus. We also investigated its association with clinical and metabolic parameters in healthy and diabetic subjects.

\section{Subjects and methods}

Subjects The 24 DNA samples from Korean subjects for the initial sequencing were randomly selected from unrelated local residents with no history of familial diseases. With 24 samples (48 chromosomes), it might be expected that more than $90 \%$ of SNPs had a frequency greater than 0.05 [17]. We studied 762 unrelated patients with type 2 diabetes (age: $59 \pm 10$ years, onset age: $50 \pm 10$ years; 356 men, 406 women) and 303 non-diabetic control subjects (age: $65 \pm 4$ years; 139 men, 164 women). All subjects who enrolled in this study were of Korean ethnicity. Type 2 diabetes was diagnosed according to World Health Organization criteria [18]. We excluded subjects who were positive for GAD antibodies and started insulin treatment within 1 year of diagnosis, and those who were ketosis prone. We divided the patients with type 2 diabetes into subgroups as follows: (1) early-onset diabetes (age at diagnosis: $25 \leq<40$ years, $n=119$; 71 men, 48 women); (2) average-onset diabetes (age at diagnosis: $40 \leq<60$ years, $n=507$; 230 men, 277 women); and (3) late-onset diabetes (age at diagnosis: $\geq 60$ years, $n=136$; 55 men, 81 women). Differences in genotype frequencies were compared between the non-diabetic group and each of the groups defined according to age of diagnosis. Selection of non-diabetic control subjects was done according to the following criteria: (1) 60 years or older; (2) no past history of diabetes; (3) no diabetes in first-degree relatives; (4) a fasting plasma glucose concentration of less than $6.1 \mathrm{mmol} / \mathrm{l}$; and (5) an $\mathrm{HbA}_{1} \mathrm{c}$ value of less than 5.8\%. The Institutional Review Board of the Clinical Research Institute at Seoul National University Hospital approved the study protocol, and informed consent for genetic analysis was obtained from each subject. All study subjects were examined the morning after an overnight fast. The parameters measured were height,

Table 1 Clinical characteristics of study subjects

\begin{tabular}{|c|c|c|c|c|c|c|c|}
\hline & $\begin{array}{l}\text { Control } \\
(n=303)\end{array}$ & $\begin{array}{l}\text { Type } 2 \text { diabetes } \\
(n=762)\end{array}$ & $p$ value $^{\mathrm{a}}$ & $\begin{array}{l}\text { Early-onset } \\
(n=119)\end{array}$ & $\begin{array}{l}\text { Average-onset } \\
(n=507)\end{array}$ & $\begin{array}{l}\text { Late-onset } \\
(n=136)\end{array}$ & $\begin{array}{l}p \\
\text { value }^{\mathrm{b}}\end{array}$ \\
\hline Sex (men:women) & $139: 164$ & $356: 406$ & 0.803 & $71: 48$ & $230: 277$ & $55: 81$ & 0.005 \\
\hline Age (years) & $65 \pm 4$ & $59 \pm 10$ & $<0.001$ & $50 \pm 11$ & $59 \pm 7$ & $70 \pm 6$ & $<0.001$ \\
\hline $\begin{array}{l}\text { Age of diagnosis of } \\
\text { diabetes (years) }\end{array}$ & & $50 \pm 10$ & & $34 \pm 4$ & $50 \pm 5$ & $65 \pm 4$ & $<0.001$ \\
\hline Duration of diabetes (years) & & $9 \pm 8$ & & $15 \pm 10$ & $9 \pm 7$ & $5 \pm 4$ & $<0.001$ \\
\hline BMI $\left(\mathrm{kg} / \mathrm{m}^{2}\right)$ & $23.7 \pm 3.1$ & $24.4 \pm 2.9$ & 0.001 & $24.1 \pm 3.1$ & $24.4 \pm 2.8$ & $24.8 \pm 2.9$ & 0.018 \\
\hline Waist $(\mathrm{cm})$ & $82.9 \pm 8.1$ & $87.3 \pm 8.0$ & $<0.001$ & $85.2 \pm 8.2$ & $87.2 \pm 7.8$ & $89.9 \pm 7.9$ & 0.093 \\
\hline Hip (cm) & $92.8 \pm 6.0$ & $96.8 \pm 6.1$ & $<0.001$ & $95.5 \pm 5.9$ & $96.7 \pm 6.0$ & $98.2 \pm 6.2$ & 0.031 \\
\hline $\begin{array}{l}\text { Systolic blood pressure } \\
(\mathrm{mmHg})\end{array}$ & $132 \pm 19$ & $135 \pm 20$ & 0.002 & $132 \pm 18$ & $135 \pm 20$ & $137 \pm 20$ & 0.012 \\
\hline $\begin{array}{l}\text { Diastolic blood pressure } \\
(\mathrm{mmHg})\end{array}$ & $81 \pm 12$ & $81 \pm 12$ & 0.219 & $80 \pm 11$ & $81 \pm 12$ & $81 \pm 12$ & 0.425 \\
\hline $\begin{array}{l}\text { Fasting plasma glucose } \\
(\mathrm{mmol} / \mathrm{l})\end{array}$ & $5.1 \pm 0.5$ & $8.6 \pm 2.6$ & $<0.001$ & $9.1 \pm 3.1$ & $8.6 \pm 2.6$ & $8.0 \pm 2.0$ & 0.440 \\
\hline Plasma insulin (pmol/1) & $50.9(5.7-202.3)$ & $68.9(7.9-857.4)$ & $<0.001$ & $71.4(7.9-450.6)$ & $68.2(7.9-857.4)$ & $71.0(9.3-472.1)$ & 0.242 \\
\hline $\mathrm{HbA}_{1} \mathrm{c}(\%)$ & $5.2 \pm 0.4$ & $8.1 \pm 1.6$ & $<0.001$ & $8.5 \pm 1.6$ & $8.1 \pm 1.6$ & $7.7 \pm 1.5$ & 0.035 \\
\hline Cholesterol (mmol/l) & $5.1 \pm 0.9$ & $5.1 \pm 1.0$ & 0.244 & $5.1 \pm 0.9$ & $5.2 \pm 2.0$ & $5.1 \pm 0.9$ & 0.262 \\
\hline Triglycerides (mmol/l) & $3.2(0.9-13.7)$ & $3.7(0.9-28.8)$ & $<0.001$ & $3.5(1.1-14.1)$ & $3.7(0.9-28.8)$ & $3.4(1.0-13.8)$ & 0.107 \\
\hline HDL cholesterol (mmol/l) & $1.2 \pm 0.3$ & $1.2 \pm 0.3$ & $<0.001$ & $1.2 \pm 0.3$ & $1.2 \pm 0.3$ & $1.2 \pm 0.3$ & 0.249 \\
\hline
\end{tabular}

Data are given as means \pm SD in the case of normal distribution, and otherwise as medians (range). $p$ values of BMI and waist and hip circumference were adjusted for age and sex. $p$ values of blood pressure, fasting plasma glucose, plasma insulin, $\mathrm{HbA}_{1} \mathrm{c}$ and lipid profiles were adjusted for age, sex and BMI

${ }^{a}$ Type 2 diabetes vs controls; b between groups defined according to age at diagnosis of type 2 diabetes 
weight, waist and hip circumference and blood pressure. Blood samples were drawn for biochemical measurements (fasting plasma glucose, fasting plasma insulin, $\mathrm{HbA}_{1} \mathrm{c}$, total cholesterol, triglycerides and HDL cholesterol) and DNA extraction. The clinical characteristics of the study population are shown in Table 1. Compared with the nondiabetic control subjects, the patients with type 2 diabetes were younger and had higher values for BMI, waist circumference, systolic blood pressure, fasting plasma glucose, fasting insulin and triglycerides; they had lower HDL cholesterol concentrations. Age, sex, duration of diabetes, BMI, systolic pressure and $\mathrm{HbA}_{1} \mathrm{c}$ levels were different between patients with early-onset, average-onset and lateonset type 2 diabetes.

Screening for SNPs in the PPARGC1A gene We sequenced exons and their boundaries of the PPARGC1A gene, including the promoter region $(\sim 1.5 \mathrm{~kb})$, to discover genetic variants in 24 Korean DNA samples using a DNA analyser (ABI PRISM 3700; Applied Biosystems, Foster City, CA, USA). Twenty-three primer sets of PPARGC1A for the amplification and sequencing analysis were designed based on GenBank sequences (Reference genome sequence for PPARGC1A; NT_006316.15 released in August 2004). Information regarding the primers used is available on our website (http://www.snp-genetics.com/reference/ PGC1_add_info.doc). Sequence variants were verified using chromatograms.

Genotyping of SNPs detected Among identified polymorphisms, eight SNPs (g. $-1789 \mathrm{G}>\mathrm{A}$, g. $-1437 \mathrm{C}>\mathrm{T}$, g.616 43T $>$ C. g.61647T $>$ C $[\mathrm{L} 251 \mathrm{~S}]$, g.61719T $>$ C, g. $75919 \mathrm{G}>\mathrm{A}$ [G482S], g.76874C $>$ T [T612M] and g.97329A $>$ G) were selected based on location (promoter, exon and exon-intron boundary), frequency ( $>0.05$ in the regulatory region and $>0.1$ in the intron), linkage disequilibrium (LD) status and haplotype tagging status. The eight relatively frequent polymorphisms were genotyped by fluorescence polarisation detection. Amplifying primers and probes were designed for TaqMan [19]. Information regarding the primers is available on our website (http://www.snp-genetics.com/ reference/PGC1_add_info.doc). With the TaqMan method, more than $97 \%$ success rate was usually obtained for ge-

a

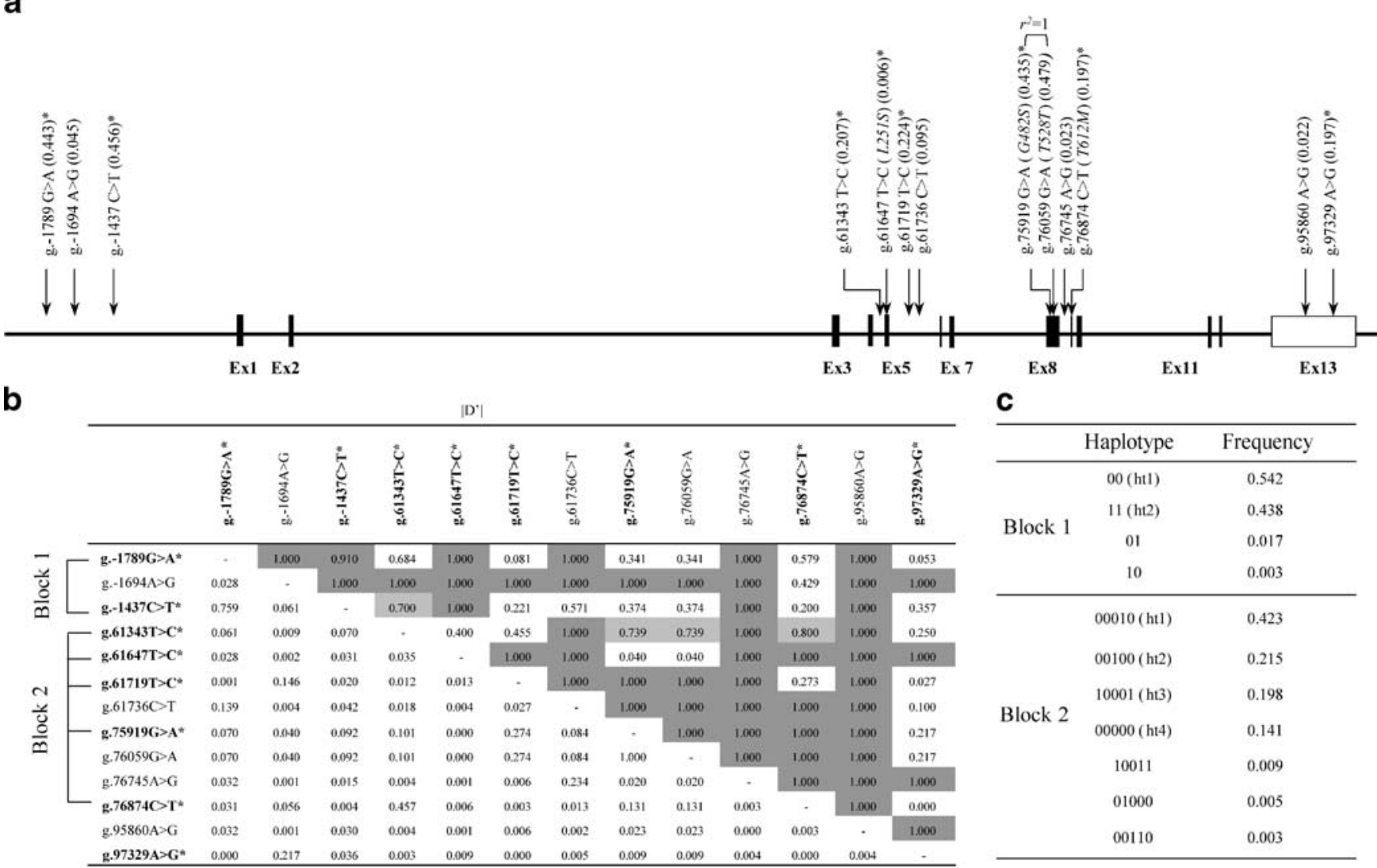

Fig. 1 a. Map of PPARGC1A on chromosome 4p15.1: polymorphisms identified. Coding exons are marked by shaded blocks and 5' and 3' untranslated regions are marked by white blocks. Asterisks (*) indicate SNPs that were genotyped in the larger population. The frequencies of SNPs without larger scale genotyping were based on sequencing data $(n=24)$. The first nucleotide of the translational start site is denoted as nucleotide plus one (reference sequence of
PPARGC1A: NT 006316.15). b. LD coefficients $\left(\left|D^{\prime}\right|\right.$ and $\left.r^{2}\right)$ among SNPs in PPARGC $\bar{C} 1 A$. Dark grey, $\left|D^{\prime}\right|>0.90$; light grey, $\left|D^{\prime}\right|>0.70$. c. Frequencies of PPARGC1A haplotypes. Block 1 haplotypes: 0, morecommon allele (g. $-1789 \mathrm{G}$, g. $-1437 \mathrm{C}) ; 1$, less-common allele (g. $-1789 \mathrm{~A}$, g. $-1437 \mathrm{~T})$. Block 2 haplotypes: 0, more-common allele (g.61343T, g.61647T, g. 61719T, g.75919G, g.76874C); 1, less-common allele (g.61343C, g.61647C, g.61719C, g.75919A, g.76874C) 
notype. No mismatchings were detected among 10\% of duplicates in 384 plates.

Statistics Differences in genotype frequencies were compared using the chi square test or the chi square test for trend. Genotypes were given codes of 0,1 and 2; 0,1 and 1; and 0,0 and 1 in the additive, dominant and recessive models, respectively. To approximate a normal distribution, triglycerides, fasting insulin and homeostasis model assessment of insulin resistance (HOMA-IR) were log transformed before analysis. For association analyses of diabetes-related phenotypes, age, sex and BMI were adjusted using a general linear regression procedure (genotypes for dominant and recessive models, as well as sex, were entered fixed factor; genotypes for additive models, age and BMI were entered covariate). We examined Lewontin's $D^{\prime}\left(\left|D^{\prime}\right|\right)$ and the LD coefficient $r^{2}$ between all pairs of biallelic loci [20]. Haplotypes of each individual were inferred using the algorithm developed by Stephens et al. [21] (PHASE), which is a Bayesian approach incorporating a priori expectations of haplotypic structure based on population genetics and coalescent theory. A $p$ value of less than 0.05 was considered statistically significant.

Table 2 Genotype distributions of the PPARGC1A gene in patients with type 2 diabetes and non-diabetic controls

\begin{tabular}{|c|c|c|c|c|}
\hline Locus & Genotype & $\begin{array}{l}\text { Diabetes } \\
(n=762)\end{array}$ & $\begin{array}{l}\text { Control } \\
(n=303)\end{array}$ & $\begin{array}{l}p \\
\text { value }\end{array}$ \\
\hline \multirow[t]{3}{*}{ g. $-1789 \mathrm{G}>\mathrm{A}$} & GG & $243(32.2)$ & $86(28.4)$ & \multirow[t]{3}{*}{0.178} \\
\hline & GA & $358(47.5)$ & $163(53.8)$ & \\
\hline & AA & $153(20.3)$ & 54 (17.8) & \\
\hline \multirow[t]{3}{*}{ g. $-1437 \mathrm{C}>\mathrm{T}$} & $\mathrm{CC}$ & $236(31.1)$ & $82(27.2)$ & \multirow[t]{3}{*}{0.105} \\
\hline & $\mathrm{CT}$ & $358(47.1)$ & $164(54.3)$ & \\
\hline & TT & $166(21.8)$ & $56(18.5)$ & \\
\hline \multirow[t]{3}{*}{ g. $61343 \mathrm{~T}>\mathrm{C}$} & $\mathrm{TT}$ & $464(61.2)$ & $201(66.0)$ & \multirow[t]{3}{*}{$0.048^{\circ}$} \\
\hline & $\mathrm{TC}$ & $263(34.7)$ & $83(27.5)$ & \\
\hline & $\mathrm{CC}$ & $31(4.1)$ & $18(6.0)$ & \\
\hline g. $61647 \mathrm{~T}>\mathrm{C}$ & TT & 737 (98.9) & $286(98.6)$ & \multirow[t]{3}{*}{0.680} \\
\hline \multirow[t]{2}{*}{$(L 251 S)$} & $\mathrm{TC}$ & $8(1.1)$ & $4(1.4)$ & \\
\hline & $\mathrm{CC}$ & $0(0)$ & $0(0)$ & \\
\hline \multirow[t]{3}{*}{ g. $61719 \mathrm{~T}>\mathrm{C}$} & $\mathrm{TT}$ & 461 (61.9) & $176(60.7)$ & \multirow[t]{3}{*}{0.359} \\
\hline & $\mathrm{TC}$ & 247 (33.2) & $93(32.1)$ & \\
\hline & $\mathrm{CC}$ & $37(5.0)$ & $21(7.2)$ & \\
\hline \multirow{3}{*}{$\begin{array}{l}\text { g. } 75919 \mathrm{G}>\mathrm{A} \\
(G 482 S)\end{array}$} & GG & $251(33.1)$ & $88(29.1)$ & \multirow[t]{3}{*}{0.117} \\
\hline & GA & $355(46.8)$ & $163(54.0)$ & \\
\hline & AA & $152(20.1)$ & $51(16.9)$ & \\
\hline g. $76874 C>T$ & $\mathrm{CC}$ & $470(62.5)$ & $205(68.3)$ & \multirow[t]{3}{*}{$0.037^{\circ}$} \\
\hline \multirow[t]{2}{*}{$(T 612 M)$} & $\mathrm{CT}$ & 255 (33.9) & $79(26.3)$ & \\
\hline & TT & $27(3.6)$ & $16(5.3)$ & \\
\hline \multirow[t]{3}{*}{ g. $97329 A>G$} & AA & $519(68.5)$ & $198(65.6)$ & \multirow[t]{3}{*}{0.613} \\
\hline & $\mathrm{AG}$ & 219 (28.9) & $94(31.1)$ & \\
\hline & GG & $20(2.6)$ & $10(3.3)$ & \\
\hline
\end{tabular}

Genotype distributions are shown as number (\%). $p$ values were calculated using the chi square test

${ }^{a} p$ values were not significant after correction for multiple comparisons (significant: $p<0.0063$ )

\section{Results}

After screening for SNPs in the PPARGC1A gene, 13 SNPs were identified and eight common SNPs were selected for larger scale genotyping (Fig. 1a). The genotype distributions of the eight SNPs were in Hardy-Weinberg equilibrium. There was no significant association between individual PPARGC1A SNPs and type 2 diabetes after correction for multiple comparisons (Table 2). Haplotype blocks were constructed using LD patterns $\left(\left|D^{\prime}\right|>0.7\right)$, and two blocks were found in this study (Fig. 1b). We selected common haplotypes (frequency $>0.05$ ) from each block, which account for $97.7-98.0 \%$ of the observed haplotypes (Fig. 1c). However, there was no significant association between common haplotypes and type 2 diabetes after correction for multiple comparisons (Table 3 ).

Next, we examined the association between the PPARG $C 1 A$ polymorphism and the age at diagnosis of type 2 diabetes or early-onset type 2 diabetes. The frequencies of g. $-1789 \mathrm{G}>\mathrm{A}$ and haplotype $h t 2(-1789 \mathrm{~A}$ and $-1437 \mathrm{~T})$ of block 1 in the promoter region were significantly different between patients with early-onset, average-onset and lateonset type 2 diabetes after correction for multiple com-

Table 3 Haplotype block distributions of the PPARGC1A gene in patients with type 2 diabetes and non-diabetic controls

\begin{tabular}{|c|c|c|c|c|}
\hline Locus & Haplotype & $\begin{array}{l}\text { Diabetes } \\
(n=762)\end{array}$ & $\begin{array}{l}\text { Control } \\
(n=303)\end{array}$ & $\begin{array}{l}p \\
\text { value }\end{array}$ \\
\hline \multicolumn{5}{|l|}{ Block 1} \\
\hline \multirow[t]{3}{*}{$h t 1$ (GC) } & $(-/-)$ & $166(21.8)$ & $59(19.5)$ & 0.092 \\
\hline & $(-/ \mathrm{ht} 1)$ & $358(47.1)$ & $165(54.5)$ & \\
\hline & (ht1/ht1) & $236(31.1)$ & $79(26.1)$ & \\
\hline \multirow[t]{3}{*}{$h t 2$ (AT) } & $(-/-)$ & $247(32.5)$ & $89(29.4)$ & 0.156 \\
\hline & $(-/ \mathrm{ht} 2)$ & $360(47.4)$ & $163(53.8)$ & \\
\hline & $(\mathrm{ht} 2 / \mathrm{ht} 2)$ & $153(20.1)$ & $51(16.8)$ & \\
\hline \multicolumn{5}{|l|}{ Block 2} \\
\hline \multirow[t]{3}{*}{$h t 1$ (TTTAC) } & $(-/-)$ & $261(34.3)$ & 93 (30.7) & 0.144 \\
\hline & $(-/$ ht 1$)$ & $354(46.5)$ & $161(53.1)$ & \\
\hline & (ht1/ht1) & $146(19.3)$ & 49 (16.2) & \\
\hline \multirow[t]{3}{*}{$h t 2$ (TTCGC) } & $(-/-)$ & $473(62.2)$ & $180(59.4)$ & 0.284 \\
\hline & $(-/ \mathrm{ht} 2)$ & $253(33.2)$ & $102(33.7)$ & \\
\hline & (ht2/ht2) & $35(4.6)$ & $21(6.9)$ & \\
\hline \multirow[t]{3}{*}{$h t 3$ (CTTGT) } & $(-/-)$ & $475(62.4)$ & $207(68.3)$ & 0.028 \\
\hline & $(-/ \mathrm{ht} 3)$ & $260(34.2)$ & $80(26.4)$ & \\
\hline & (ht3/ht3) & $26(3.4)$ & $16(5.3)$ & \\
\hline \multirow[t]{3}{*}{$h t 4$ (TTTGC) } & $(-/-)$ & $567(74.5)$ & $229(75.6)$ & 0.464 \\
\hline & $(-/ \mathrm{ht} 3)$ & $178(23.4)$ & $71(23.4)$ & \\
\hline & $(\mathrm{ht} 3 / \mathrm{ht} 3)$ & $16(2.1)$ & $3(1.0)$ & \\
\hline
\end{tabular}

Haplotype distributions are shown as number (\%). $p$ values were calculated using chi square test. Block 1 haplotypes: g. $-1789 \mathrm{G}>\mathrm{A}$, g. $-1437 \mathrm{C}>\mathrm{T}$; block 2 haplotypes: g.61343T $>\mathrm{C}$, g.61647T $>\mathrm{C}$, g.61791T $>$ C, g.75919G $>$ A, g.76874C $>$ T. Haplotypes and their frequencies were inferred using the algorithm developed by Stephens et al. [21]. Missing genotype data were omitted for exact haplotype construction

${ }^{\mathrm{a}} p$ values were not significant after correction for multiple comparisons (significant: $p<0.0083$ ) 
Table 4 Association of PPARGC1A SNPs with age at diagnosis of type 2 diabetes and early-onset type 2 diabetes

\begin{tabular}{|c|c|c|c|c|c|c|c|c|c|}
\hline \multirow[t]{2}{*}{ Locus } & \multirow[t]{2}{*}{ Genotype } & \multirow{2}{*}{$\begin{array}{l}\text { Controls } \\
(n=303)\end{array}$} & \multicolumn{7}{|c|}{ Patients with type 2 diabetes $(n=762)$} \\
\hline & & & $\begin{array}{l}\text { Early-onset } \\
(n=119)\end{array}$ & $\begin{array}{l}p \\
\text { value }^{\mathrm{a}}\end{array}$ & $\begin{array}{l}\text { Average-onset } \\
(n=507)\end{array}$ & $\begin{array}{l}p \\
\text { value }^{\mathrm{a}}\end{array}$ & $\begin{array}{l}\text { Late-onset } \\
(n=136)\end{array}$ & $\begin{array}{l}p \\
\text { value }^{\mathrm{a}}\end{array}$ & $\begin{array}{l}p \text { value between } \\
\text { groups }^{\mathrm{b}}\end{array}$ \\
\hline \multirow[t]{3}{*}{ g. $-1789 \mathrm{G}>\mathrm{A}$} & GG & $86(28.4)$ & $44(37.3)$ & \multirow[t]{3}{*}{0.002} & $167(33.3)$ & 0.307 & $32(23.9)$ & \multirow[t]{3}{*}{0.426} & \multirow[t]{3}{*}{0.006} \\
\hline & GA & $163(53.8)$ & $41(34.7)$ & & $245(48.8)$ & & $72(53.7)$ & & \\
\hline & AA & $54(17.8)$ & $33(28.0)$ & & $90(17.9)$ & & $30(22.4)$ & & \\
\hline \multirow[t]{3}{*}{ g. $-1437 \mathrm{C}>\mathrm{T}$} & $\mathrm{CC}$ & $82(27.2)$ & $45(37.8)$ & \multirow[t]{3}{*}{0.001} & $159(31.5)$ & 0.267 & $32(23.5)$ & \multirow[t]{3}{*}{0.435} & \multirow[t]{3}{*}{$0.015^{\mathrm{c}}$} \\
\hline & $\mathrm{CT}$ & $164(54.3)$ & $41(34.5)$ & & $245(48.5)$ & & $72(52.9)$ & & \\
\hline & TT & $56(18.5)$ & $33(27.7)$ & & $101(20.0)$ & & $32(23.5)$ & & \\
\hline \multirow[t]{3}{*}{ g. $61343 \mathrm{~T}>\mathrm{C}$} & TT & $201(66.0)$ & $66(55.9)$ & \multirow[t]{3}{*}{$0.046^{\mathrm{c}}$} & $305(60.5)$ & $0.016^{\mathrm{c}}$ & $93(68.4)$ & \multirow[t]{3}{*}{0.848} & \multirow[t]{3}{*}{0.053} \\
\hline & $\mathrm{TC}$ & $83(27.5)$ & $47(39.8)$ & & $182(36.1)$ & & $34(25.0)$ & & \\
\hline & $\mathrm{CC}$ & $18(6.0)$ & $5(4.2)$ & & $17(3.4)$ & & $9(6.6)$ & & \\
\hline \multirow{3}{*}{$\begin{array}{l}\text { g.61647T }>C \\
(L 251 S)\end{array}$} & TT & $286(98.6)$ & $114(99.1)$ & \multirow[t]{3}{*}{0.675} & 495 (99.0) & 0.635 & $131(98.5)$ & \multirow[t]{3}{*}{0.920} & \multirow[t]{3}{*}{0.862} \\
\hline & $\mathrm{TC}$ & $4(1.4)$ & $1(0.9)$ & & $5(1.0)$ & & $2(1.5)$ & & \\
\hline & $\mathrm{CC}$ & $0(0)$ & $0(0)$ & & $0(0)$ & & $0(0)$ & & \\
\hline \multirow[t]{3}{*}{ g.61719T $>C$} & TT & $176(60.7)$ & $67(58.3)$ & \multirow[t]{3}{*}{0.397} & $311(62.6)$ & 0.371 & $83(62.4)$ & \multirow[t]{3}{*}{0.882} & \multirow[t]{3}{*}{0.834} \\
\hline & $\mathrm{TC}$ & $93(32.1)$ & $43(37.4)$ & & $162(32.6)$ & & $42(31.6)$ & & \\
\hline & $\mathrm{CC}$ & $21(7.2)$ & $5(4.3)$ & & $24(4.8)$ & & $8(6.0)$ & & \\
\hline \multirow{3}{*}{$\begin{array}{l}\text { g. } 75919 \mathrm{G}>A \\
(G 482 S)\end{array}$} & GG & $88(29.1)$ & $43(36.4)$ & \multirow[t]{3}{*}{0.182} & $164(32.5)$ & 0.170 & $44(32.4)$ & \multirow[t]{3}{*}{0.479} & \multirow[t]{3}{*}{0.947} \\
\hline & GA & $163(54.0)$ & $52(44.1)$ & & $238(47.2)$ & & $65(47.8)$ & & \\
\hline & AA & $51(16.9)$ & $23(19.5)$ & & $102(20.2)$ & & $27(19.9)$ & & \\
\hline g. $76874 C>T$ & $\mathrm{CC}$ & $205(68.3)$ & $70(58.8)$ & \multirow{3}{*}{0.096} & $308(61.2)$ & $0.009^{\mathrm{c}}$ & $92(70.8)$ & \multirow[t]{3}{*}{0.862} & 0.080 \\
\hline \multirow[t]{2}{*}{$(T 612 M)$} & $\mathrm{CT}$ & $79(26.3)$ & $44(37.0)$ & & $180(35.8)$ & & $31(23.8)$ & & \\
\hline & TT & $16(5.3)$ & $5(4.2)$ & & $15(3.0)$ & & $7(5.4)$ & & \\
\hline g. $97329 A>G$ & AA & $198(65.6)$ & 81 (68.6) & 0.818 & $344(68.3)$ & 0.712 & $94(69.1)$ & 0.490 & 0.902 \\
\hline & $\mathrm{AG}$ & $94(31.1)$ & $33(28.0)$ & & $146(29.0)$ & & $40(29.4)$ & & \\
\hline & GG & $10(3.3)$ & $4(3.4)$ & & $14(2.8)$ & & $2(1.5)$ & & \\
\hline
\end{tabular}

Genotype distributions are shown as number (\%). $p$ values were calculated using chi square test

${ }^{a}$ Each group defined according to age at diagnosis of type 2 diabetes vs controls; ${ }^{b}$ between groups defined according to age at diagnosis of type 2 diabetes; ${ }^{\mathrm{c}} p$ values were not significant after correction for multiple comparisons ( ${ }^{\mathrm{a}}$ significant: $p<0.0021$; ${ }^{\mathrm{b}}$ significant: $p<0.0063$ )

parisons (Tables 4, 5). Furthermore, two SNPs and $h t 1$ and $h t 2$ haplotypes of block 1 in the promoter region revealed a significant association with early-onset type 2 diabetes even after Bonferroni correction (Tables 4, 5). Since the effect of age was not our primary concern, we divided type 2 diabetic patients into quartiles according to age at diagnosis. There was a significant increasing trend in the combined proportion of variant heterozygotes and homozygotes (i.e. a dominant model) of g. $-1789 \mathrm{G}>\mathrm{A}$ and g. $-1437 \mathrm{C}>\mathrm{T}$ according to increasing quartiles of age at diagnosis of type 2 diabetes $\left(\chi^{2}\right.$ for trend $=4.138, p=0.042 ; \chi^{2}$ for trend $=$ $4.618, p=0.032$, respectively; Fig. 2).

Although there was a marginal significance level, the SNPs of g.61343T $>C$, g.76874C $>$ T $(T 612 M)$, and the haplotype $h t 3$ (61343C, 61647T, 61719T, 75919G and $76874 \mathrm{~T}$ ) of block 2 , were associated with average-onset type 2 diabetes (Tables 4, 5). In addition, their associations with type 2 diabetes were increased after the exclusion of the late-onset group ( $p=0.008, p=0.007$ and $p=0.007$, respectively).

For the association analyses of the diabetes-related phenotypes, non-diabetic control subjects and diabetic patients were treated separately. However, there was no significant association between genotypes or haplotypes of PPARG-
$C 1 A$ and fasting plasma glucose, insulin, HOMA-IR, waist circumference, BMI, blood pressure and lipid profiles when adjusting for multiple comparisons in either the control group or the diabetic group (data not shown).

\section{Discussion}

In this study, no strong association was detected between SNPs or common haplotypes of PPARGC1A and type 2 diabetes. However, we found that SNPs and haplotypes of the PPARGC1A promoter region were associated with age of diagnosis of type 2 diabetes and early-onset type 2 diabetes. To our knowledge, this is the first study to suggest that PPARGC1A promoter polymorphisms might be associated with onset age of type 2 diabetes and early-onset type 2 diabetes. However, we could not find any association with the diabetes-related phenotype. Therefore, before concluding that the genetic variations of the PPAR $G C 1 A$ promoter region are associated with early-onset type 2 diabetes, replication studies in other populations are necessary.

At this time, we can only speculate on the mechanism linking genetic variation of PPARGC1A to the susceptibil- 
Table 5 Association of PPARGC1A haplotype blocks with age at diagnosis of type 2 diabetes and early-onset type 2 diabetes

\begin{tabular}{|c|c|c|c|c|c|c|c|c|c|}
\hline \multirow[t]{2}{*}{ Locus } & \multirow[t]{2}{*}{ Genotype } & \multirow{2}{*}{$\begin{array}{l}\text { Controls } \\
(n=303)\end{array}$} & \multicolumn{7}{|c|}{ Patients with type 2 diabetes $(n=762)$} \\
\hline & & & $\begin{array}{l}\text { Early-onset } \\
(n=119)\end{array}$ & $\begin{array}{l}p \\
\text { value }^{\mathrm{a}}\end{array}$ & $\begin{array}{l}\text { Average-onset } \\
(n=507)\end{array}$ & $\begin{array}{l}p \\
\text { value }^{\mathrm{a}}\end{array}$ & $\begin{array}{l}\text { Late-onset } \\
(n=136)\end{array}$ & $\begin{array}{l}p \\
\text { value }^{\mathrm{a}}\end{array}$ & $\begin{array}{l}p \text { value between } \\
\text { groups }^{\mathrm{b}}\end{array}$ \\
\hline \multicolumn{10}{|l|}{ Block 1} \\
\hline \multirow[t]{3}{*}{$h t 1(\mathrm{GC})$} & $(-/-)$ & $56(18.5)$ & $33(27.7)$ & 0.001 & $101(20.0)$ & 0.199 & $32(23.5)$ & 0.599 & $0.015^{\mathrm{c}}$ \\
\hline & $(-/ \mathrm{ht} 1)$ & $138(45.5)$ & $41(34.5)$ & & $245(48.5)$ & & $72(52.9)$ & & \\
\hline & (ht1/ht1) & $109(36.0)$ & $45(37.8)$ & & $159(31.5)$ & & $32(23.5)$ & & \\
\hline \multirow[t]{3}{*}{$h t 2$ (AT) } & $(-/-)$ & $89(29.4)$ & $45(37.8)$ & 0.001 & $168(33.3)$ & 0.387 & $34(25.0)$ & 0.360 & 0.008 \\
\hline & $(-/ \mathrm{ht} 2)$ & $163(53.8)$ & $41(34.5)$ & & $247(48.9)$ & & $72(52.9)$ & & \\
\hline & $(\mathrm{ht} 2 / \mathrm{ht} 2)$ & $51(16.8)$ & $33(27.7)$ & & $90(17.8)$ & & $30(22.1)$ & & \\
\hline \multicolumn{10}{|l|}{ Block 2} \\
\hline$h t 1$ & $(-/-)$ & $93(30.7)$ & $45(37.8)$ & 0.261 & $170(33.6)$ & 0.201 & $46(33.8)$ & 0.486 & 0.936 \\
\hline \multirow[t]{2}{*}{ (TTTAC) } & $(-/ h t 1)$ & $161(53.1)$ & $53(44.5)$ & & $237(46.8)$ & & $64(47.1)$ & & \\
\hline & (ht1/ht1) & 49 (16.2) & $21(17.6)$ & & 99 (19.6) & & $26(19.1)$ & & \\
\hline$h t 2$ & $(-/-)$ & $180(59.4)$ & $68(57.1)$ & 0.424 & $319(63.0)$ & 0.241 & $86(63.2)$ & 0.739 & 0.644 \\
\hline \multirow[t]{2}{*}{ (TTCGC) } & $(-/ \mathrm{ht} 2)$ & $102(33.7)$ & $46(38.7)$ & & 165 (32.6) & & $42(30.9)$ & & \\
\hline & $(\mathrm{ht} 2 / \mathrm{ht} 2)$ & $21(6.9)$ & $5(4.2)$ & & $22(4.3)$ & & $8(5.9)$ & & \\
\hline$h t 3$ & $(-/-)$ & $207(68.3)$ & $70(58.8)$ & 0.099 & $312(61.7)$ & $0.009^{c}$ & $93(68.4)$ & 0.998 & 0.197 \\
\hline \multirow[t]{2}{*}{ (CTTGT) } & $(-/ h t 3)$ & $80(26.4)$ & $44(37.0)$ & & $180(35.6)$ & & $36(26.5)$ & & \\
\hline & (ht3/ht3) & $16(5.3)$ & $5(4.2)$ & & $14(2.8)$ & & $7(5.1)$ & & \\
\hline$h t 4$ & $(-/-)$ & $229(75.6)$ & $93(78.2)$ & 0.854 & $377(74.5)$ & 0.457 & $97(71.3)$ & 0.262 & 0.667 \\
\hline \multirow[t]{2}{*}{ (TTTGC) } & $(-/ h t 3)$ & $71(23.4)$ & $25(21.0)$ & & $118(23.3)$ & & $35(25.7)$ & & \\
\hline & $(\mathrm{ht} 3 / \mathrm{ht} 3)$ & $3(1.0)$ & $1(0.8)$ & & $11(2.2)$ & & $4(2.9)$ & & \\
\hline
\end{tabular}

Haplotype distributions are shown as number (\%). Block 1 haplotypes: g. $-1789 \mathrm{G}>\mathrm{A}$, g. $-1437 \mathrm{C}>\mathrm{T}$; block 2 haplotypes: g.61343T $>\mathrm{C}$, g.61647T $>$ C, g.61791T $>$ C, g.75919G $>$ A, g.76874C $>$ T. Haplotypes and their frequencies were inferred using the algorithm developed by Stephens et al. [21]. Missing genotype data were omitted for exact haplotype construction. $p$ values were calculated using chi square test ${ }^{a}$ Each group defined according to age at diagnosis of type 2 diabetes vs controls; between groups defined according to age at diagnosis of type 2 diabetes; ${ }^{c} p$ values were not significant after correction for multiple comparisons ( ${ }^{\mathrm{a}}$ significant: $p<0.0028$; ${ }^{\mathrm{b}}$ significant: $p<0.0083$ )

ity of early-onset type 2 diabetes. Interestingly, the constructs harbouring g. $-1437 \mathrm{C}$ (g. $-1422 \mathrm{C}$ in the previous study) revealed increased reporter gene activity independent of MEF-2C expression in HepG2 cells compared with the constructs harbouring g. $-1437 \mathrm{~T}$ [16], although the SNPs at g. -1789 and g. -1437 are located within putative MEF-2C binding sites in the murine [22] and human [16] gene. Increased expression of PGC- $1 \alpha$ in the liver enhanced hepatic gluconeogenesis $[3,4,6]$, and increased
PGC- $1 \alpha$ expression in pancreatic beta cells blunted the glucose-induced insulin release [2]. Therefore, the SNP of g. $-1437 \mathrm{C}$, which displayed increased promoter activity in the hepatoma cell line, could contribute to the pathogenesis of early-onset type 2 diabetes. However, increased expression of PGC- $1 \alpha$ in skeletal muscle enhances glucose uptake by induction of GLUT-4 expression, and thereby improves the glucose tolerance [5]. At this time, it is unclear whether the promoter effects of g. $-1437 \mathrm{C}>\mathrm{T}$ are

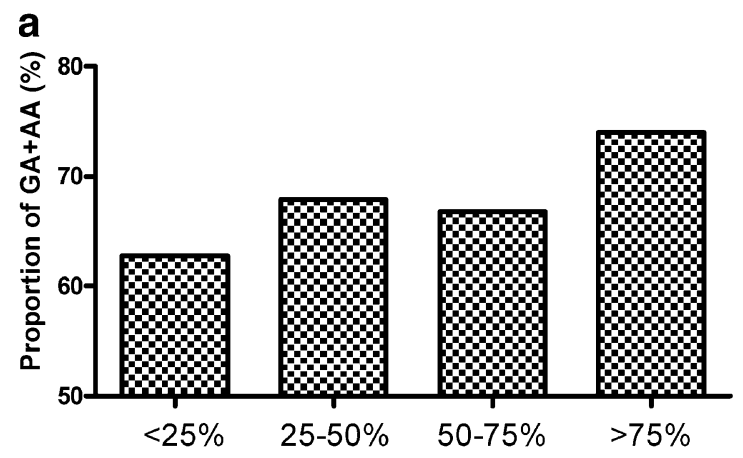

Quartiles of age at diagnosis of type 2 diabetes

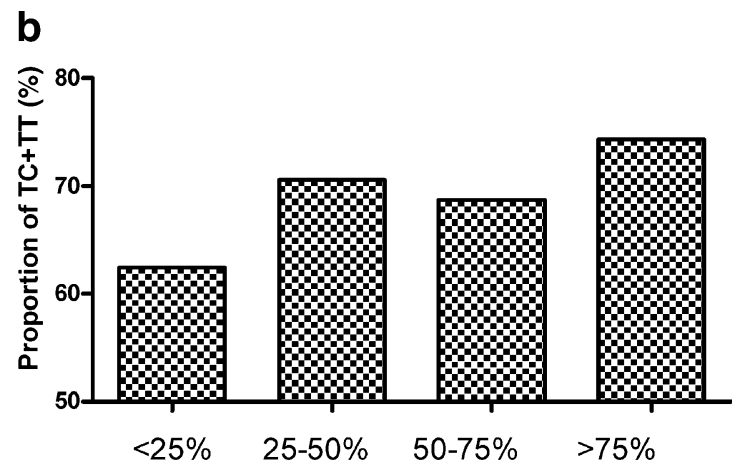

Quartiles of age at diagnosis of type 2 diabetes

betes. Bar charts show that the variant proportion of g. $-1789 \mathrm{G}>\mathrm{A}$ and g. $-1437 \mathrm{C}>\mathrm{T}$ in a dominant model increased with higher age at

diagnosis ( $p=0.042$ and $p=0.032$, respectively)
Fig. 2 The combined proportion of variant heterozygotes and homozygotes (i.e. a dominant model) of (a) g. $-1789 \mathrm{G}>\mathrm{A}$ and (b) g. $-1437 \mathrm{C}>\mathrm{T}$ according to quartiles of age at diagnosis of type 2 dia- 
tissue-specific or whether this polymorphism is in linkage disequilibrium with other SNPs of PPARGC1A located in more forward promoter regions that revealed allele- and tissue-specific promoter effects [16]. Regarding the association between the PPARGC1A polymorphism and the age of onset of type 2 diabetes mellitus, it is interesting that skeletal muscle expression of PGC-1 $\alpha$ was reduced not only in type 2 diabetic patients but also in non-diabetic subjects with a family history of type 2 diabetes when compared with control subjects $[7,8]$. Expression in skeletal muscle was influenced by ageing and the PPARGC1A polymorphism, and the effects of the PPARGC1A polymorphism on skeletal muscle expression were age-dependent [23]. The age-dependent effects of the PPARGC1A polymorphism suggest that the association between PPAR $G C 1 A$ genetic variation and type 2 diabetes might be different for different generations [23].

In this study, we could not replicate the association between type 2 diabetes and g.75919G $>$ A (G482S) [12], which is also known to be associated with insulin resistance and early insulin secretion [13, 15] although there was no significant association in other reports $[14,16]$. However, our study did not have sufficient power to detect an association between the $G 482 S$ polymorphism and the risk of type 2 diabetes (power $0.445, \alpha$ error 0.05 ), assuming the genotype risk is similar to that of patients in a Danish study [12]. Interestingly, the SNPs at g.61343T $>$ C and g.76874T $>\mathrm{C}(T 612 M)$ were associated with age at diagnosis of type 2 diabetes. In addition, the SNPs at g.613 $43 \mathrm{~T}>\mathrm{C}$ and g.76874C $>\mathrm{T}(\mathrm{T} 612 M)$, and the $h t 3(61343 \mathrm{C}$, 75919G, 61647T, 61719T and 76874T) haplotype, were associated with type 2 diabetes after exclusion of the lateonset group. In particular, g.76874C $>\mathrm{T}(T 612 M)$ has been reported to be associated with type 2 diabetes [12]. In contrast to $G 482 S$, this allele is conserved between human beings and mice [12].

There were a few limitations of our study design. Our study was not designed to detect susceptibility effects attributable to rare variants, nor was it designed to investigate whether variants influence several intermediate traits relevant to the pathogenesis of type 2 diabetes. Since we mainly screened the regions of the promoter, the exon and the exon-intron boundary, it may not be possible to detect susceptibility effects due to variants lying some distance from the 'core' gene elements.

In conclusion, we found that SNPs and haplotypes of $P P A R G C 1 A$ genes, especially within the promoter region, were significantly associated with age of diagnosis of type 2 diabetes and early-onset type 2 diabetes in the Korean population. Our observations suggest that the genetic variation of PPARGC1A might be useful for the detection of subjects genetically susceptible to early-onset type 2 diabetes.

Acknowledgements J. H. Kim and H. D. Shin contributed equally to this work. This work was supported by a grant from the Korea Health 21 R \& D Project, Ministry of Health \& Welfare, Republic of Korea (00-PJ3-PG6-GN07-001).

Duality of interest. No duality of interest is declared.

\section{References}

1. Puigserver P, Wu Z, Park CW et al (1998) A cold-inducible coactivator of nuclear receptors linked to adaptive thermogenesis. Cell 92:829-839

2. Yoon JC, Xu G, Deeney JT et al (2003) Suppression of beta cell energy metabolism and insulin release by PGC-1alpha. Dev Cell 5:73-83

3. Louet JF, Hayhurst G, Gonzalez FJ, Girard J, Decaux JF (2002) The coactivator PGC-1 is involved in the regulation of the liver carnitine palmitoyltransferase I gene expression by cAMP in combination with HNF4 alpha and cAMP-response elementbinding protein (CREB). J Biol Chem 277:37991-38000

4. Yoon JC, Puigserver P, Chen G et al (2001) Control of hepatic gluconeogenesis through the transcriptional coactivator PGC-1. Nature 413:131-138

5. Michael LF, Wu Z, Cheatham RB et al (2001) Restoration of insulin-sensitive glucose transporter (GLUT4) gene expression in muscle cells by the transcriptional coactivator PGC-1. Proc Natl Acad Sci U S A 98:3820-3825

6. Koo SH, Satoh H, Herzig S et al (2004) PGC-1 promotes insulin resistance in liver through PPAR-alpha-dependent induction of TRB-3. Nat Med 10:530-534

7. Patti ME, Butte AJ, Crunkhorn S et al (2003) Coordinated reduction of genes of oxidative metabolism in humans with insulin resistance and diabetes: potential role of PGC1 and NRF1. Proc Natl Acad Sci U S A 100:8466-8471

8. Mootha VK, Lindgren CM, Eriksson KF et al (2003) PGC1alpha-responsive genes involved in oxidative phosphorylation are coordinately downregulated in human diabetes. Nat Genet $34: 267-273$

9. Pratley RE, Thompson DB, Prochazka M et al (1998) An autosomal genomic scan for loci linked to prediabetic phenotypes in Pima Indians. J Clin Invest 101:1757-1764

10. Arya R, Duggirala R, Jenkinson CP et al (2004) Evidence of a novel quantitative-trait locus for obesity on chromosome $4 p$ in Mexican Americans. Am J Hum Genet 74:272-282

11. Taylor R (2004) Causation of type 2 diabetes - the Gordian knot unravels. N Engl J Med 350:639-641

12. Ek J, Andersen G, Urhammer SA et al (2001) Mutation analysis of peroxisome proliferator-activated receptor-gamma coactivator-1 (PGC-1) and relationships of identified amino acid polymorphisms to type II diabetes mellitus. Diabetologia 44: $2220-2226$

13. Hara K, Tobe K, Okada T et al (2002) A genetic variation in the PGC-1 gene could confer insulin resistance and susceptibility to type II diabetes. Diabetologia 45:740-743

14. Lacquemant C, Chikri M, Boutin P, Samson C, Froguel P (2001) No association between the G482S polymorphism of the proliferator-activated receptor-gamma coactivator-1 (PGC-1) gene and type II diabetes in French Caucasians. Diabetologia 45:602-603

15. Muller YL, Bogardus C, Pedersen O, Baier L (2003) A Gly482Ser missense mutation in the peroxisome proliferatoractivated receptor gamma coactivator- 1 is associated with altered lipid oxidation and early insulin secretion in Pima Indians. Diabetes 52:895-898

16. Oberkofler H, Linnemayr V, Weitgasser R et al (2004) Complex haplotypes of the PGC-1alpha gene are associated with carbohydrate metabolism and type 2 diabetes. Diabetes 53:13851393

17. Eberle MA, Kruglyak L (2000) An analysis of strategies for discovery of single-nucleotide polymorphisms. Genet Epidemiol 19[Suppl 1]:S29-S35

18. Alberti KG, Zimmet PZ (1998) Definition, diagnosis and classification of diabetes mellitus and its complications: part 1. Diagnosis and classification of diabetes mellitus provisional report of a WHO consultation. Diabet Med 15:539-553 
19. Livak KJ (1999) Allelic discrimination using fluorogenic probes and the 5' nuclease assay. Genet Anal 14:143-149

20. Hedrick P, Kumar S (2001) Mutation and linkage disequilibrium in human mtDNA. Eur J Hum Genet 9:969-972

21. Stephens M, Smith NJ, Donnelly P (2001) A new statistical method for haplotype reconstruction from population data. Am J Hum Genet 68:978-989
22. Czubryt MP, McAnally J, Fishman GI, Olson EN (2003) Regulation of peroxisome proliferator-activated receptor gamma coactivator 1 alpha (PGC-1 alpha) and mitochondrial function by MEF2 and HDAC5. Proc Natl Acad Sci U S A 100:17111716

23. Ling C, Poulsen P, Carlsson E et al (2004) Multiple environmental and genetic factors influence skeletal muscle PGC-1 alpha and PGC-1 beta gene expression in twins. J Clin Invest 114:1518-1526 